\title{
The Decoupling of Affluence and Waste Discharge under Spatial Correlation: Do Richer Communities Discharge More Waste?
}

By

\author{
Daisuke Ichinose \\ Masashi Yamamoto \\ Yuichiro Yoshida
}

July 2011

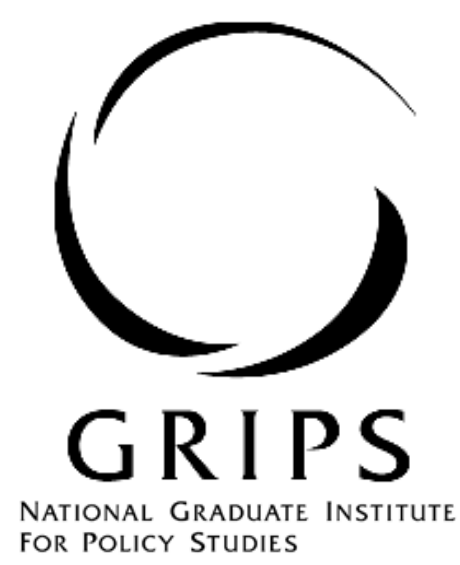

National Graduate Institute for Policy Studies

7-22-1 Roppongi, Minato-ku,

Tokyo, Japan 106-8677 


\title{
The Decoupling of Affluence and Waste Discharge under Spatial Correlation: Do Richer Communities Discharge More Waste?*
}

\author{
Daisuke ICHINOSE $^{\dagger} \quad$ Masashi YAMAMOTO $\ddagger$ Yuichiro YOSHIDA Y $^{\S}$
}

July 2011

\begin{abstract}
Although there are many studies on the environmental Kuznets curve, very few of them address municipal solid waste cases, and there is still controversy concerning the validity of the waste Kuznets curve hypothesis. In this paper, we provide empirical evidence for the waste Kuznets curve hypothesis by applying spatial econometrics methods to municipal-level data in Japan. To our knowledge, this is the first study that finds valid evidence for the waste Kuznets curve hypothesis in the absolute decoupling manner. The successful result owes in part to our highly disaggregated data and also to the use of a spatial econometric model that takes into account the mimicking behavior among neighboring municipalities. The former indicates that distinguishing between household and business waste is the key to revealing the waste-income relationship, while the latter implies the importance of peer effects when municipal governments formulate waste-reduction policies.
\end{abstract}

\section{Introduction}

The compatibility between economic growth and environmental protection has been one of the most relevant research questions in the field of environmental economics, which a number of researchers have devoted considerable effort to identify. ${ }^{1}$ One hypothesis that seems to have won a consensus regarding this compatibility is the environmental Kuznets curve hypothesis. The environmental Kuznets curve hypothesis claims that an economy tends to degrade its environmental quality during its takeoff for economic growth, yet beyond a certain threshold, its environmental quality starts to improve as per-capita income continues to grow. Many researchers support the environmental Kuznets curve hypothesis by measuring the environmental quality using indicators such as sulfur dioxide and suspended particulate

\footnotetext{
*The authors are grateful to the Research Center of National Graduate Institute for Policy Studies (GRIPS) and the University of Toyama KYOUSEI Project for their financial support.

${ }^{\dagger}$ Assistant Professor, Tohoku University of Community Service and Science, 3-5-1 Iimoriyama, Sakata, Yamagata 998-8580, JAPAN, Email: ichinose@koeki-u.ac.jp

${ }^{\ddagger}$ Corrensponding Author. Associate Professor, Center for Far Eastern Studies, University of Toyama, 3190 Gofuku, Toyama, Japan 930-8555, Email: myam@eco.u-toyama.ac.jp, Tel: +81-76-445-6455.

$\S$ Associate Professor, National Graduate Institute for Policy Studies, 7-22-1 Roppongi, Minato-ku, Tokyo, Japan 106-8677, Email: yoshida@grips.ac.jp

${ }^{1}$ The next section provides an overview.
} 
matter generated per capita. However, there are still several types of environmental indicators that have been controversial regarding the validity of the environmental Kuznets curve hypothesis. One such indicator is municipal solid waste (MSW). When the environmental quality is measured in terms of waste generation per capita, the environmental Kuznets curve hypothesis is specifically called the waste Kuznets curve (WKC) hypothesis. While waste problems are a serious environmental issue for many countries with high economic activities, and are becoming more acute in many rapidly developing countries, there is a lack of solid empirical evidence on whether the per-capita waste generation follows the path predicted by the WKC hypothesis. By using highly disaggregated data in Japan, this paper provides the very first empirical evidence that the MSW and per-capita income follow the relationship predicted by the WKC.

The contribution of our paper stems from its highly disaggregated data. In this paper, we reexamine the WKC hypothesis by introducing two types of disaggregation in the data set, namely, spatial disaggregation and disaggregation by waste source. One of the potential reasons that previous studies such as Cole et al. (1997) and Mazzanti and Zoboli (2009) failed in verifying the WKC hypothesis is that they used country-level data. Often the definition of waste varies from country to country, and the results of cross-country analysis are inevitably biased. Moreover, country-level data inadvertently neglect the heterogeneity among municipalities in the same country, say, between Beverly Hills in California and Kodiak Island in Alaska, which can be potentially more significant than cross-country differences between, say, the US and Canada. We, therefore, use municipality-level data instead, focusing on the spatial disaggregation within one country.

As for the waste source, our data distinguish two different types of MSW, according to origin, namely household MSW and business MSW. Business MSW is defined as the waste generated by small businesses, offices, restaurants, and schools. On one hand, it is understood that household waste is directly related to the income of residents in the municipality, but on the other hand, business 
waste is not, because many people commute to offices or schools from distant municipalities. Besides, businesses and households follow different decision-making processes in discharging waste. Combining these two different types of MSW into a single figure, therefore, inhibits identification of any robust relationship between income levels and the amount of waste discharge. ${ }^{2}$ We thus expect an inverted U-shaped relationship between household MSW and per-capita income, as predicted by the WKC hypothesis.

Our a-priori conjecture on the behavior of Japanese municipal governments calls for an assumption of spatial correlation in our econometric model. In Japan, each of some 1,700 municipalities belongs to one of 47 prefectures. Under this two-tiered system, municipalities in the same prefecture tend to share the same information and regulations provided by their prefectural government, and follow suit in policy making. Consequently, a municipality tends to 'mimic' the behavior of its neighbors, thus generating a strong peer effect. Given that this mimicking behavior is prevalent, the naive OLS estimator is biased. In order to accommodate such a potential 'contiguity effect' among municipalities in our data, we specify our model in the manner of spatial econometrics allowing either the dependent variables or errors to be spatially correlated. Specifically, we estimate both a spatial lag model (SLM) and a spatial error model (SEM). The typical presumption about (Japanese) municipal governments is that they tend to mimic each other more in their ways of making waste-reduction efforts, and rather less in the actual amount of waste reduction. Unfortunately, these efforts are typically unmeasurable or unavailable as quantitative data, and, hence, are regarded as omitted variables in our analysis. Should this presumption be true, then the errors, rather than the amounts of waste, are spatially correlated.

Through the use of the above-mentioned disaggregated data and the spatial estimation procedure,

\footnotetext{
${ }^{2}$ To our knowledge, no study considers the disaggregation in the type of MSW discharged along with spatial disaggregation at the municipal level. Mazzanti et al. (2009) use municipal-level data from Italy. Although Berrens et al. (1997) and Wang et al. (1998) also use within-country data for the US, these studies focus on the environmental Kuznets curve hypothesis for hazardous waste and do not focus on the hypothesis for MSW.
} 
we find that the WKC hypothesis does hold for household MSW, and, as expected, it does not hold for business MSW. The robust estimation of spatial econometric models proves that both SLM and SEM are statistically sound, concluding that Japanese municipal governments mimic each other in making efforts for waste-reduction, as well as paying attention to their neighbors' achievements.

The rest of this paper consists of the following. In section 2, we briefly discuss the previous research on the WKC. Section 3 explains the status quo of Japan's solid waste management in order to understand properly the following sections. In Section 4, we show the results of our regression analysis with cross-sectional data and interpret the results. Section 6 summarizes the discussion above and presents policy implications.

\section{Summary of Previous Research}

One of the earliest studies on the WKC hypothesis was performed by Cole et al. (1997). They used OECD panel data for 1975-1990 and examined the environmental Kuznets curve hypothesis for several environmental indicators, including municipal waste. As a result, they found that the environmental Kuznets curve hypothesis holds for indicators such as sulfur dioxide and suspended particulate matter, but does not hold for municipal waste. In later years, Fischer-Kowalski and Amann (2001) and Karousakis (2009) examined the WKC hypothesis by using more recent panel data from OECD countries, but these studies did not find evidence for the WKC hypothesis. Mazzanti and Zoboli (2009) examined EU panel data and found evidence for the environmental Kuznets curve hypothesis in the case of landfill waste but not in the case of MSW discharge. One of the few studies that support the environmental Kuznets curve hypothesis for waste is Raymond (2004). He used international cross-sectional data and found evidence for the WKC hypothesis. However, because he used a waste/consumption indicator as an explanatory variable, the result cannot be applied directly to the case of MSW, which is the focus of our study.

Although most studies on the WKC hypothesis use cross-country data, there are some papers 
that focus on within-country data. Berrens et al. (1997) and Wang et al. (1998) examined the environmental Kuznets curve hypothesis for hazardous waste by using county-level, cross-sectional data in the US, and both found evidence for the environmental Kuznets curve hypothesis. More recently, Mazzanti et al. (2008) examined the validity of the environmental Kuznets curve hypothesis for MSW by using panel data from Italy. They succeeded in showing relative de-linking for waste generation (ascending pass of an inverted U shape of the environmental Kuznets curve) but did not find the evidence of absolute de-linking (descending side of an inverted $U$ shape of the environmental Kuznets curve).

Thus, there is little evidence that suggests the validity of the WKC hypothesis. All of the positive evidence concerns cases of hazardous waste and the waste/consumption indicator, and none of the previous studies has proven the evidence of the environmental Kuznets curve hypothesis for MSW. Mazzanti and Zoboli (2009) mentioned that one of the reasons that the WKC hypothesis is not observed in their analysis is that their data are too aggregated. They also suggested that future empirical work on the WKC or environmental Kuznets curve hypotheses should be performed with highly disaggregated data. We show the results of our empirical work with more disaggregated data in the following section. Indeed, there are few studies that conduct spatial disaggregation (using within-country data), and no studies consider disaggregation in the waste type.

As for the spatial econometric aspect, the previous environmental Kuznets curve research using a spatial econometric approach is very limited. Nicolli et al. (2010) is similar to our study in that they analyze waste generation and landfill amount in Italy but their spatial analysis is based on Moran's I-statistic alone. Our method is more closely related to Kim et al. (2003) and Maddison (2006) in that both models, SLM and SEM, are estimated. The primary focus of Kim et al. (2003) is hedonic pricing not the environmental Kuznets curve hypothesis, and Maddison (2006) is different since it performed the empirical environmental Kuznets curve analysis of sulfur dioxide, nitrogen oxide, and others for 
country-level data in the EU, and no waste-related indicators are involved. The details of our own estimation strategy for our spatial models are explained in the following section.

\section{State of Municipal Solid Waste in Japan}

In Japan, waste is largely classified into two categories: industrial waste and domestic waste. Technically, the Waste Disposal and Public Cleansing Law defines waste generated by industrial activity as industrial waste and the rest as domestic waste. A typical example of industrial waste is waste generated by a factory, and the typical example of domestic waste is waste generated by households, small businesses, restaurants, convenience stores, or office buildings. Thus, in the case of Japan, domestic waste corresponds to MSW that is usually applied in the study of the WKC hypothesis.

In addition, Japanese MSW can be classified into two types: domestic waste from households and domestic waste from business activities. As defined in the previous section, we label the former type of waste as household MSW and the latter type as business MSW. Figure 1 depicts the classification of waste in Japan.

\section{////// Figure 1 around here. //////}

Because chapter four of the Waste Disposal and Public Cleansing Law stipulates that each municipality has a responsibility for making its own plan for disposing MSW generated in its region, waste management policies for MSW widely differ across municipalities. For example, some municipalities collect plastics as combustible waste, while other municipalities collect plastics as incombustible refuse. For recyclable waste, some municipalities pick up only packaging materials, while others collect waste paper or used textiles, in addition to packaging materials. This means that a municipality can be considered as an independent decision-making entity for waste management. Thus, aggregating the data, say, at the national level, might hide some effects caused by different waste management policies among municipalities. Therefore, we use data at the municipality level in our empirical analysis. 


\section{/////// Table 1 around here. //////}

As for waste disposal practice, a high rate of incineration and a low rate of landfill are considered features of Japan. Table 1 shows these points. Japan's incineration rate is about $74 \%$, while the second largest rate globally is $54 \%$ for Denmark. As for the rate of landfill, it is also very small, although other countries whose national land areas are very limited, e.g., the Netherlands, also have very small rates of landfill in their waste generation.

\section{Empirical Analysis}

\subsection{The econometric model}

To test the WKC hypothesis, we use the most common specification used in the environmental Kuznets curve literature, namely,

$$
y_{i}=\beta_{0}+\beta_{1} x_{i}+\beta_{2} x_{i}^{2}+\gamma^{\prime} z_{i}+\epsilon_{i}
$$

where $y_{i}$ is MSW per capita in municipality $i ; x_{i}$ is per-capita income of each $i$; and $z_{i}$ is the vector of other related variables in municipality $i$. Note that parameters $\beta_{0}, \beta_{1}, \beta_{2}$ are scalars and $\gamma$ is a vector. If in our regression model, the parameters satisfy $\beta_{1}>0$ and $\beta_{2}<0$, then the derived curve is an inverted U-shaped curve, which implies that the WKC hypothesis is confirmed.

Following Anselin (2001) and other methods of spatial econometrics, we consider two basic spatial econometric models: the spatial lag model and the spatial error model. Suppose there exist $N$ regions (municipalities) in the data. The spatial lag model is

$$
y_{i}=\beta_{0}+\lambda w_{i}^{L}+\beta_{1} x_{i}+\beta_{2} x_{i}^{2}+\gamma^{\prime} z_{i}+\epsilon_{i} .
$$

Parameter $\lambda$ is a spatial autocorrelation coefficient and $w_{i}^{L}$ is $i$ th element of $W y$ where $W$ is the spatial weight matrix defined below and $y$ is a vector of our dependent variables, say MSW per capita. We assume that $\epsilon_{i}$ is independently and identically distributed. We also assume that municipalities 
are considered as contiguous if they are in the same prefecture. When $i$ th municipality is contiguous with $j$ th municipality in our spatial weight matrix, the $(i, j)$ element of the spatial weight matrix is unity in our case. For instance, if there are three municipalities in each of two prefectures A and B (see Figure 2), the spatial weight matrix looks like that below.

\begin{tabular}{c|cccccc} 
& A1 & A2 & A3 & B1 & B2 & B3 \\
\hline A1 & 0 & 1 & 1 & 0 & 0 & 0 \\
A2 & 1 & 0 & 1 & 0 & 0 & 0 \\
A3 & 1 & 1 & 0 & 0 & 0 & 0 \\
B1 & 0 & 0 & 0 & 0 & 1 & 1 \\
B2 & 0 & 0 & 0 & 1 & 0 & 1 \\
B3 & 0 & 0 & 0 & 1 & 1 & 0
\end{tabular}

////// Figure 2 around here. //////

Then, our actual spatial matrix, $W$, is

$$
W=\left[\begin{array}{ccccc}
D_{1} & 0 & 0 & \cdots & 0 \\
0 & D_{2} & 0 & \cdots & 0 \\
0 & 0 & D_{3} & \cdots & 0 \\
\vdots & \vdots & \vdots & \ddots & \vdots \\
0 & 0 & 0 & \cdots & D_{K}
\end{array}\right]
$$

where

$$
D_{k}=\left[\begin{array}{ccccc}
0 & 1 & 1 & \cdots & 1 \\
1 & 0 & 1 & \cdots & 1 \\
1 & 1 & 0 & \cdots & 1 \\
\vdots & \vdots & \vdots & \ddots & \vdots \\
1 & 1 & 1 & 1 & 0
\end{array}\right]
$$

Note that $K(=47)$ is the number of prefectures in our case. As is assumed in Kim et al. (2003) and others, the diagonal elements of $D_{k}$ in the spatial weight matrix are set to zero and the row elements are standardized as one when we use (4) in the actual estimation. Because of the endogeneity problem in the spatial lag term, the simple OLS estimator is not appropriate. Thus, we estimate the spatial lag model through maximum likelihood estimation (see Anselin (2001) for details). With our large sample $(N=1,798)$, we can expect that the maximum likelihood estimator, $\hat{\beta}_{M L}$, is asymptotically consistent ( $\operatorname{plim} \hat{\beta}_{M L}=\beta$ ). Thus, this estimator has the same theoretical properties as that derived by the two-step OLS method. 
The other econometric specification is the spatial error model. In this model, the spatial effect comes through the error terms: Formally,

$$
y_{i}=\beta_{0}+\beta_{1} x_{i}+\beta_{2} x_{i}^{2}+\gamma^{\prime} z_{i}+\mu_{i}
$$

where

$$
\mu_{i}=\rho w_{i}^{E}+\epsilon_{i}
$$

Note that $w_{i}^{E}$ is $i$ th element in vector $W \mu$ and $\epsilon_{i}$ values are assumed to be independent and identically distributed errors. Because the OLS estimators are biased, we estimate the SEM by using the maximum likelihood method.

Although we assume there is a contiguity effect in our WKC model, there is no proof for it. We therefore test whether the spatial specification is appropriate using the Lagrange multiplier (LM) test. In addition, we test if the spatial lag model is more suitable than the SEM (and vice versa) by using the robust LM test (see Anselin (2001) for details).

We expect that the SEM is the preferred model. Our assumption of the contiguity effect is that municipalities in the same prefecture always observe and follow one another, sometimes in an intangible way. For example, when a municipality starts a new public policy, say, an educational program to reduce the generation of household waste, it is often observed that other neighboring municipalities will 'mimic' the policy.

In contrast, the behavioral assumption in the spatial lag model is that municipalities care about the waste generation of their neighbors, which we consider unlikely. Rather, households or business owners are affected by tangible and intangible policies introduced by the 'mimicking' local government. In most cases, the intangible behavior cannot be measured by the data. If the contiguity effect exists, it appears in the error term because of the missing variables problem, that is, what we define as the spatial error model. 


\subsection{Data}

For the following empirical analysis, we developed a municipality-level, cross-sectional data set for Japan in 2005. In our data set, the waste-related data were obtained from the Japanese Ministry of the Environment (2008), and other socioeconomic data, such as income per capita or population density, were from the Ministry of Internal Affairs and Communications (2008).

There are two main reasons why we use cross-sectional data rather than panel data. The most important reason stems from the large number of municipality mergers led by the national government during the late 1990s to the mid-2000s. In fact, the total number of municipalities was reduced to more than half the original number by the mergers. These municipality mergers caused an attrition problem that seriously damages the reliability of panel data ${ }^{3}$. The other reason arises from the availability of socioeconomic data. Because crucial socioeconomic data, such as household composition, are released only every five years, we cannot develop panel data that include sufficient longitudinal information. For these reasons, we apply cross-sectional data for the latest available data, from 2005, in the following analysis.

\section{////// Table 2 around here. //////}

Table 2 shows the descriptive statistics of the variables that we use. In Table 2, waste is the total MSW generation per capita (unit: kilograms per day per capita) in a municipality. These data can be disaggregated into two classes, wasteh and wasteb. The former is household MSW, and the latter is business MSW. Because, as described above, the relationship between income level and the amount of waste discharge will be different between households and businesses, it is desirable to separate the waste into household MSW and business MSW when we analyze the WKC hypothesis.

landfill means the per-capita amount of waste finally put into landfill (unit: tons per capita). Unfortunately, because there are no available data, we cannot divide landfill waste into two types

\footnotetext{
${ }^{3}$ See Wooldridge (2002, chapter 17) for details.
} 
(landfill waste discharged from households and landfill waste from small businesses), unlike the case of waste generation.

The most important nonwaste variable in this study is income. This is defined as total taxable gains (unit: million Yen) in a municipality. perinc (million Yen per capita) is simply calculated by dividing income by the number of income tax payers, which means that perinc is considered the income per household, not income per capita. perinc2 is the square of perinc.

To identify the effect of other waste-related policies, we define hrpice and sorting. hprice is a dummy variable that takes unity if a municipality introduces the unit pricing for either combustible or noncombustible waste. Under the assumption of the rationality of the behavior of households, we expect less waste generation from households if a unit-based pricing is introduced ${ }^{4}$. sorting is the number of separated waste items when a household throws away waste. For instance, a municipality collects combustible waste, noncombustible waste, used paper, used plastics, and metals separately, while another municipality collects most of these waste types (or recyclables) together. We suppose that sorting has a negative sign since those who are familiar with more time-consuming sorting practices, namely, with larger sorting, are aware of reducing the waste generation. Note that local governments can decide that the MSW policies, pricing policies, and sorting practices are quite different among municipalities.

We also use other socioeconomic variables that will affect waste generation. shousehold is the ratio of single-person households to total households. We expect that there is less per-capita MSW generated if there are more than two people in a household. elderly is the ratio of elderly-couple households to the total ${ }^{5}$, and we expect that an elderly household generates less per-capita MSW compared with younger households because the amount of goods consumed by elderly people will be

\footnotetext{
${ }^{4}$ We only use the dummy variable of the unit-based pricing for household MSW because most of the municipalities have already introduced unit-based pricing for business MSW.

${ }^{5}$ An elderly-couple household is defined as a household that is composed of a husband aged 65 years or over and a wife aged 60 years or over.
} 
less than that of younger people.

commutein indicates the ratio derived by dividing the number of commuters from areas outside the municipality by the number of people who commute from the municipality to elsewhere. We believe that this variable indicates the level of economic activity because economically growing municipalities provide employment opportunities for more people and, thus, attract people living outside the municipality. We expect that commutein is positively related to the amount of waste discharged and landfill waste. Finally, popden denotes the population density (population per 1,000 $\mathrm{m}^{2}$ ).

\section{Estimation}

\subsection{Evidence from the empirical analysis}

First, we show the results for waste generation, which are rarely significant in previous empirical studies. In our analysis, we use three types of independent variables as indicators for waste discharge: waste, wasteh, and wasteb. Tables 3,4 , and 5 summarize the results.

////// Table 3 around here. //////

////// Table 4 around here. //////

////// Table 5 around here. //////

To confirm the WKC hypothesis, a positive sign on the estimated parameter of perinc and a negative sign on perinc2 are necessary. For total waste generation (waste) in Table 3 and household MSW (wasteh) in Table 4, the estimated parameter on perinc2 is negative and statistically significant, and the parameter on perinc is positive and significant. This is evidence for the WKC hypothesis. On the other hand, for business MSW (wasteb) in Table 5, these two coefficients are insignificant. These results imply that whether or not the WKC hypothesis holds depends on the type of MSW. Because of the waste-type disaggregation, the result clarifies that the WKC hypothesis does hold for 
household MSW but does not hold for business MSW. We consider this result more closely in the following section.

Table 6 also shows the results of the landfill case. In this case, the two coefficients on income are not significant, which means landfill waste does not support the WKC hypothesis. This result is inconsistent with most of the results in previous studies, such as Mazzanti and Zoboli (2009).

The signs of perinc and perinc2 are both consistent with a theoretical explanation of the WKC hypothesis. However, the result indicates that landfill correlates less strongly with the per-capita income of households. In fact, in the case of the spatial error model, $\beta_{1}$ and $\beta_{2}$ are not significant at the $10 \%$ level. This may be because the amount of landfill waste is largely affected by whether a local government has its own landfill site, which is determined by the geographical conditions of the municipality and not by its income level. Because it is difficult for a municipality with a small area to have its own landfill site, it has to use a landfill site in other municipalities and pay the fees required. Thus, a municipality without its own landfill site will try to decrease the amount of landfill waste regardless of its income level.

////// Table 6 around here. //////

We also find interesting results in the case of socioeconomic variables. Tables 3 , 4 , and 5 indicate that the amounts of each type of waste generated significantly increase as the ratio of single-person households increases. These results are consistent with our expectations.

In relation to household composition, the results show that the higher the ratio of elderly households, the lower the amount of waste discharge. This might be because the amount of goods consumed by elderly people is less than that consumed by younger people, as discussed in the previous section. On the other hand, the ratio of elderly households seems to be positively related to the amount of landfill waste. Although this result contradicts the case of waste discharge, it is less statistically significant. Thus, the relationship between the ratio of elderly households and the amount of landfill waste 
is considered to be weak.

commutein is positively and significantly related to all the dependent variables. As noted above, this variable indicates the level of economic activity. Therefore, it is quite natural to find that the amount of discharged waste and landfill waste increases as commutein increases. In turn, population density decreases the amount of discharged waste and landfill waste, as we expected. As for the policy variables, we can show that the signs of hprice and sorting are significantly positive for total MSW and household MSW. This means that the charge for garbage collection and the increase in the number of waste separations significantly decrease the amount of these wastes.

\subsection{Discussion}

In terms of the WKC hypothesis, it is important to check whether the turning point of the curve is contained in the observed income level. Following the definition by OECD (2002), we conclude that it is absolute decoupling if the turning point is in the range of the observed income data. If not, we state that it is relative decoupling. As mentioned in section 2, none of the previous studies observed absolute decoupling with household solid waste. Table 7 shows a summary of our studies. These results are calculated by deriving the first-order conditions of (1), (2), and (5) with respect to perinc and solving for perinc.

For our estimates, as is shown in Table 7, absolute decoupling has been observed for total waste (the sum of household MSW and business MSW) and household MSW.

////// Table 7 around here. //////

////// Figure 3 around here. //////

Figure 3 is a graphical illustration of turning points. Note that two legends are used for the vertical axes, and their magnitudes are irrelevant to our discussion on turning points. Because average percapita income is 3.03 with a minimum of 2.11 and a maximum of 5.95 , absolute decoupling is definitely 
observed.

The most interesting finding in our analysis is that the environmental Kuznets curve hypothesis does holds for household MSW, but does not hold for business MSW. This result suggests that the applicability of the WKC hypothesis is dependent upon who generates the waste. Recall that business waste is defined as the waste generated by small businesses, restaurants, and schools. Because many people commute to offices or schools from distant municipalities, business waste is not necessarily related to the incomes of the people living in the municipality. Business waste should also relate to the incomes of people living in the distant municipalities. On the other hand, it is understood that household waste is directly related to the incomes of the people living in the municipality. For this reason, the waste-income relationship is distinctly different for households and businesses.

Therefore, making no distinction between household MSW and business MSW is one of the possible reasons why the previous literature could not find evidence for the WKC hypothesis. Because whether the WKC hypothesis holds or not largely depends on the waste type, aggregating the type of waste, as done in previous studies, makes it difficult to find evidence for the WKC hypothesis. None of the previous studies considered the failure to confirm the WKC hypothesis in this regard.

This paper is the first research to analyze the spatial effect on the WKC hypothesis through the spatial lag model and the SEM. For the tests of spatial treatment, all the LM tests $\left(L M_{e r r}\right.$ and $\left.L M_{l a g}\right)$ are statistically significant, which means OLS estimators are inappropriate to investigate the WKC hypothesis. The robust LM tests $\left(R L M_{\text {err }}\right.$ and $\left.R L M_{\text {lag }}\right)$ are also significant for all the dependent variables. This indicates that we cannot select either the spatial lag model or the SEM as a proper specification. It is worth mentioning that this result confirms the validity of the WKC hypothesis regardless of the model selection.

Our initial assumption was that the SEM would be selected because a household is affected by neighboring municipalities through intangible mimicking behavior (e.g., education programs and public 
advertisements encouraging waste reduction). Intangible effects appear in the error term as a missing variable. In addition to the SEM, we found that the spatial lag model is also appropriate for our analysis. This means that municipal governments care what their neighbors do in terms of waste generation. This point has not been mentioned in the previous empirical works.

\section{Conclusion}

In this paper, we showed that there is sufficient evidence for the existence of the WKC hypothesis in Japan. This successful result has been brought about by introducing two types of data disaggregation: spatial disaggregation, using highly disaggregated data within one country; and disaggregation in terms of waste types. In particular, waste types have not been separated in previous literature. In addition, we use a spatial econometrics approach that can capture the mimicking behavior of municipalities.

Because of these modifications, we provide a significant contribution to the existing literature by showing that household waste does support the WKC hypothesis while business waste does not. It is obvious that the relationship between income level and the amount of waste discharged is different between households and businesses. The business MSW is, for example, likely to be affected by percapita income only in an indirect manner. To discern these two might be the key to confirming the WKC hypothesis for MSW generation.

Though the result shows that the amount of total waste and household waste decreases when the income level becomes sufficiently high, this does not deny the necessity of applying policies to reduce waste. Indeed, because the absolute amount of waste discharge still remains at a high level, even if the income level of a municipality exceeds the turning point, it is important to continue efforts to reduce waste discharge. Moreover, the result indicates the importance of separating the waste types in the context of policy making because the relationship between income level and the amount of waste is explicitly different for households and businesses. In this regard, our research indicates that the waste problem will be settled by well-designed policies that reflect the differences between the types of MSW. 


\section{References}

Anselin, L. (2001) "Spatial Econometrics," in Baltagi, B.H. ed. A Companion to Theoretical Econometrics, Basil Blackwell, pp. 310330.

Berrens, R.P., Bohara, A.K., Gawande, K., and Wang, P. (1997) "Testing the inverted-U hypothesis for US hazardous waste: An application of the generalized gamma model," Economics Letters, 55, 435440.

Cole, M., Rayner, A., and Bates, J. (1997) "The EKC: An empirical analysis," Environment and Development Economics, 2, 401416.

Japanese Ministry of the Environment (2008) State of Discharge and Treatment of Municipal Solid Waste (each year).

Kim, C.W., Phipps, T., and Anselin, L. (2003) "Measuring the benefits of air quality improvement: A spatial hedonic approach," Journal of Environmental Economics and Management, 45, 2439.

Kinnaman, T. (2009) "The economics of municipal solid waste management," Waste Management, 29, 26152617.

Maddison, D. (2006) "Environmental Kuznets curves: A spatial econometric approach," Journal of Environmental Economics and Management, 51, 218230.

Mazzanti, M., and Montini, A. eds. (2009) Waste and Environmental Policy, Routledge Explorations in Environmental Economics.

Mazzanti, M., Montini, A., and Zoboli, R. (2008) "Municipal waste generation and socioeconomic drivers," Journal of Environment and Development, 17, 5169.

Mazzanti, M., and Zoboli, R. (2009) "Municipal waste Kuznets curves: Evidence on socio-economic drivers and policy effectiveness from the EU," Environmental and Resource Economics, 44, 203230.

Ministry of Internal Affairs and Communications (2008) The System of Social and Demographic Statistics of Japan.

Nicolli, F., Mazanti, M., and Montini, A. (2010) "Waste generation and landfill diversion dynamics: decentralised management and spatial effects, "Fondazione Eni Enrico Mattei Working Papers, No. 417.

OECD (2002) Indicators to Measure Decoupling of Environmental Pressure from Economic Growth, Paris: OECD. 
Raymond, L. (2004) "Economic growth as environmental policy? Reconsidering the environmental Kuznets curve," Journal of Public Policy, 24, 327348.

Vehlow, J., Bergfeldt, B., and Visser, R. (2007) "European Union waste management strategy and the importance of biogenic waste," Journal of Material Cycle and Waste Management, 9, 130139.

Wang, P., Bohara, A.K., Berrens, R.P., and Gawande, K. (1998) "A risk-based environmental Kuznets curve for US hazardous waste sites," Applied Economics Letters, 5, 761763.

Wooldridge, J.M. (2002) "Econometric Analysis of Cross Section and Panel Data," MIT Press. 


\section{A Figures}

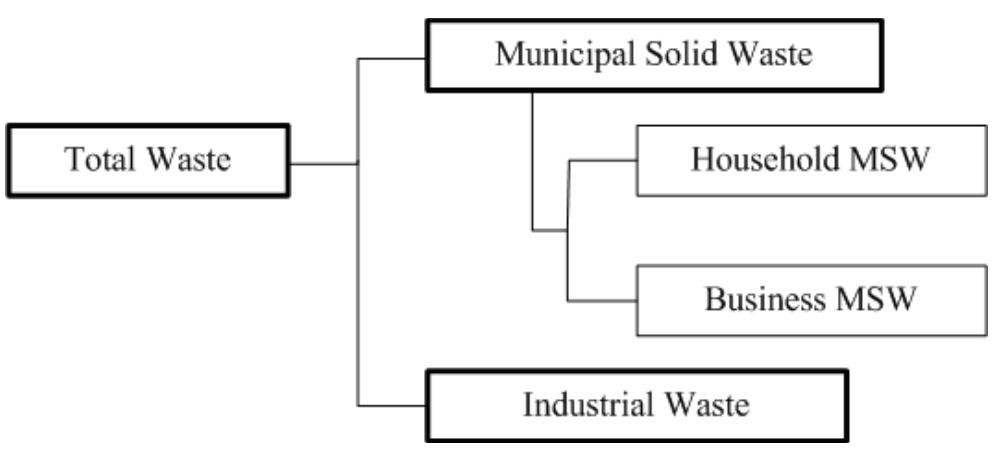

source: Ministry of Environment

Figure 1: Classification of waste in Japan 


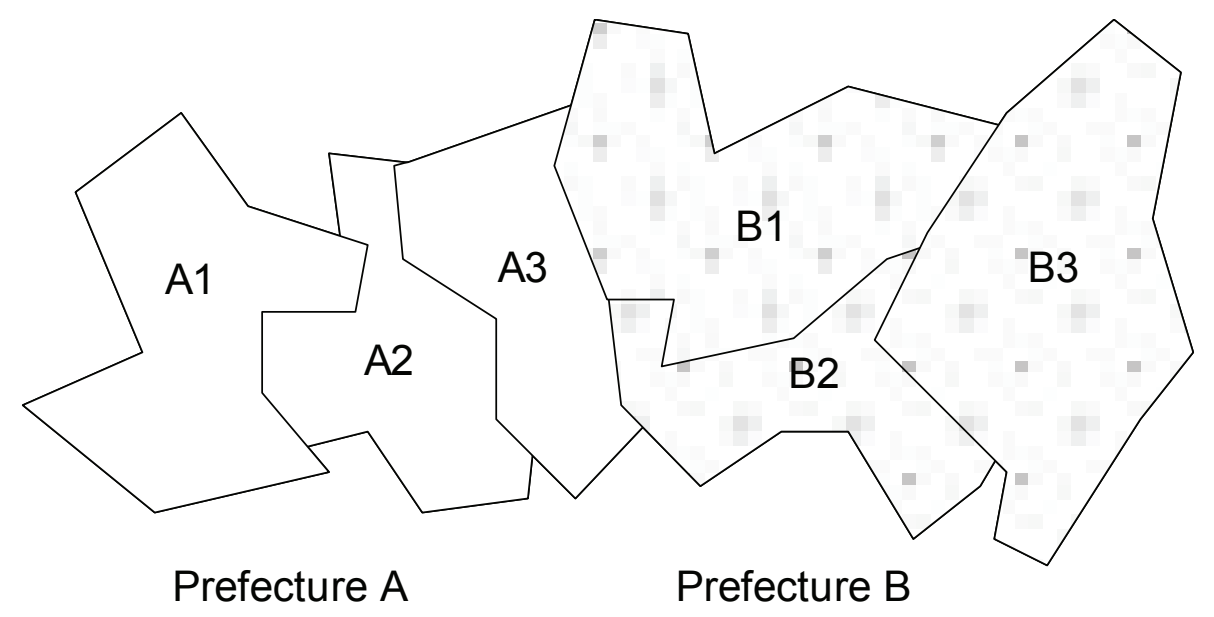

Figure 2: Example of the relationship between municipalities and prefectures 


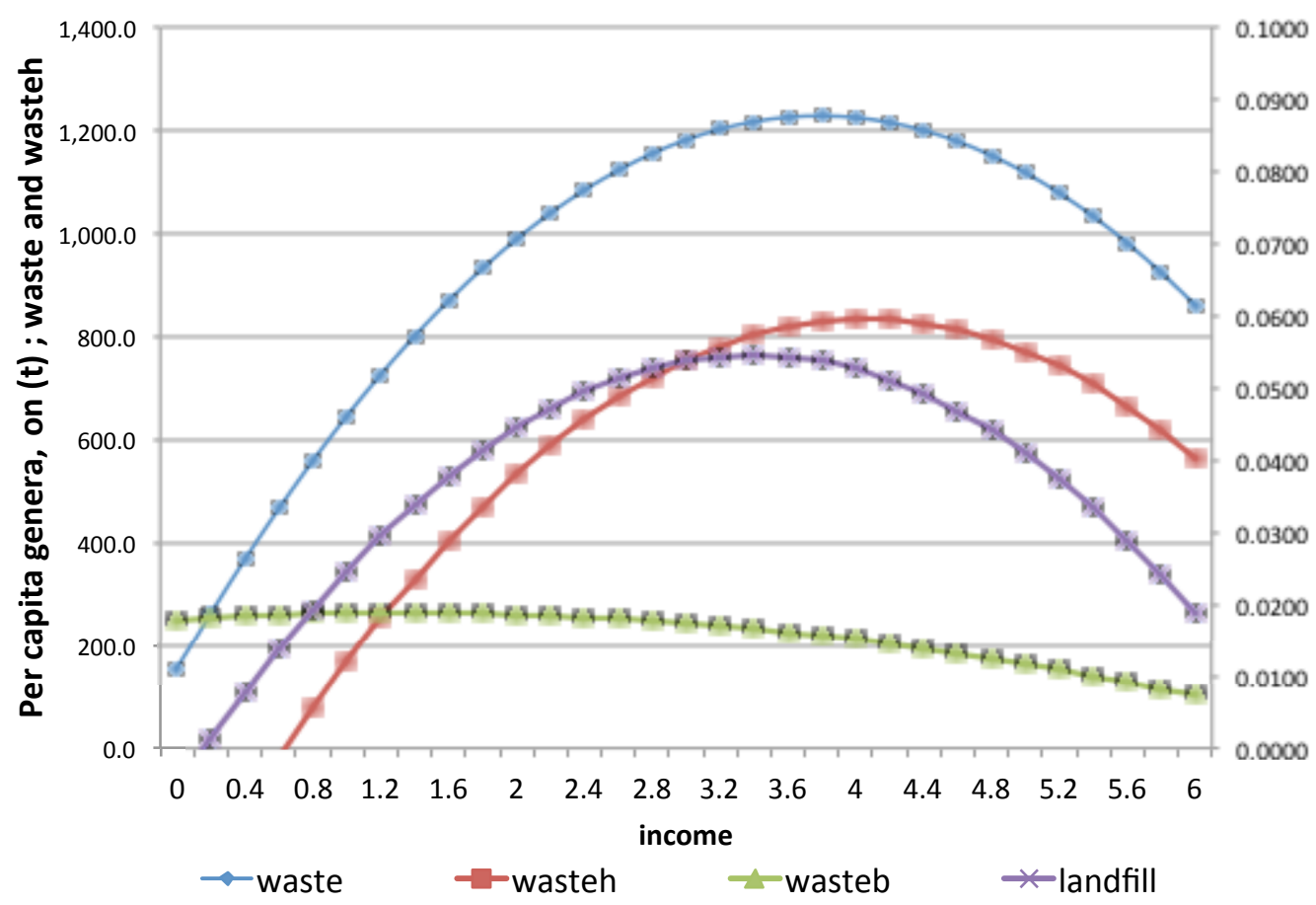

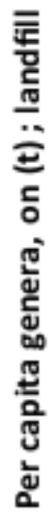

Figure 3: Turning points of MSW and landfill 


\section{B Tables}

Table 1: Per-capita generation of MSW, incineration, and landfill rate in 2004

\begin{tabular}{lrrr}
\hline \hline Country & MSW (kg/year) & Incineration (\%) & Landfill (\%) \\
\hline Austria & 627 & 22 & 20 \\
Belgium & 469 & 33 & 10 \\
Denmark & 696 & 54 & 4 \\
France & 567 & 33 & 38 \\
Germany & 600 & 24 & 17 \\
Italy & 538 & 11 & 57 \\
Japan & 396 & 78 & 4 \\
The Netherlands & 624 & 34 & 2 \\
Spain & 662 & 6 & 55 \\
Sweden & 464 & 47 & 9 \\
United Kingdom & 600 & 8 & 69 \\
\hline
\end{tabular}

Source: Vehlow et al. (2007) and MOE (2008) 
Table 2: Summary statistics

\begin{tabular}{lrrrrr}
\hline \hline \multicolumn{1}{c}{ Variable } & \multicolumn{1}{c}{ Mean } & (Std. Dev.) & Min. & Max. & N \\
\hline waste & 983.73 & $(367.28)$ & 148.33 & 6876.98 & 1,798 \\
wasteh & 743.95 & $(277.26)$ & 148.33 & 6414.28 & 1,798 \\
wasteb & 239.78 & $(199.94)$ & 0 & 3091.43 & 1,798 \\
landfill & 0.05 & $(0.06)$ & 0 & 1.19 & 1,798 \\
\hline commutein & 1.11 & $(2.42)$ & 0.13 & 63 & 1,798 \\
elderly & 0.11 & $(0.04)$ & 0.02 & 0.29 & 1,798 \\
hprice & 0.49 & $(0.5)$ & 0 & 1 & 1,798 \\
income & 88,801 & $(270,743)$ & 320 & $6,690,409$ & 1,798 \\
perinc & 3.03 & $(0.42)$ & 2.11 & 5.95 & 1,798 \\
pop & 65,747 & $(172,813)$ & 214 & $3,579,628$ & 1,798 \\
popden & 0.84 & $(1.71)$ & 0.001 & 13.73 & 1,798 \\
shousehold & 0.23 & $(0.07)$ & 0.07 & 0.69 & 1,798 \\
sorting & 11.53 & $(4.66)$ & 2 & 26 & 1,798 \\
\hline
\end{tabular}

Note 1: The first four variables are independent variables, all of which are on a per-capita basis. Note 2: See the text for sources and units. 
Table 3: Estimation results: total municipal solid waste (waste)

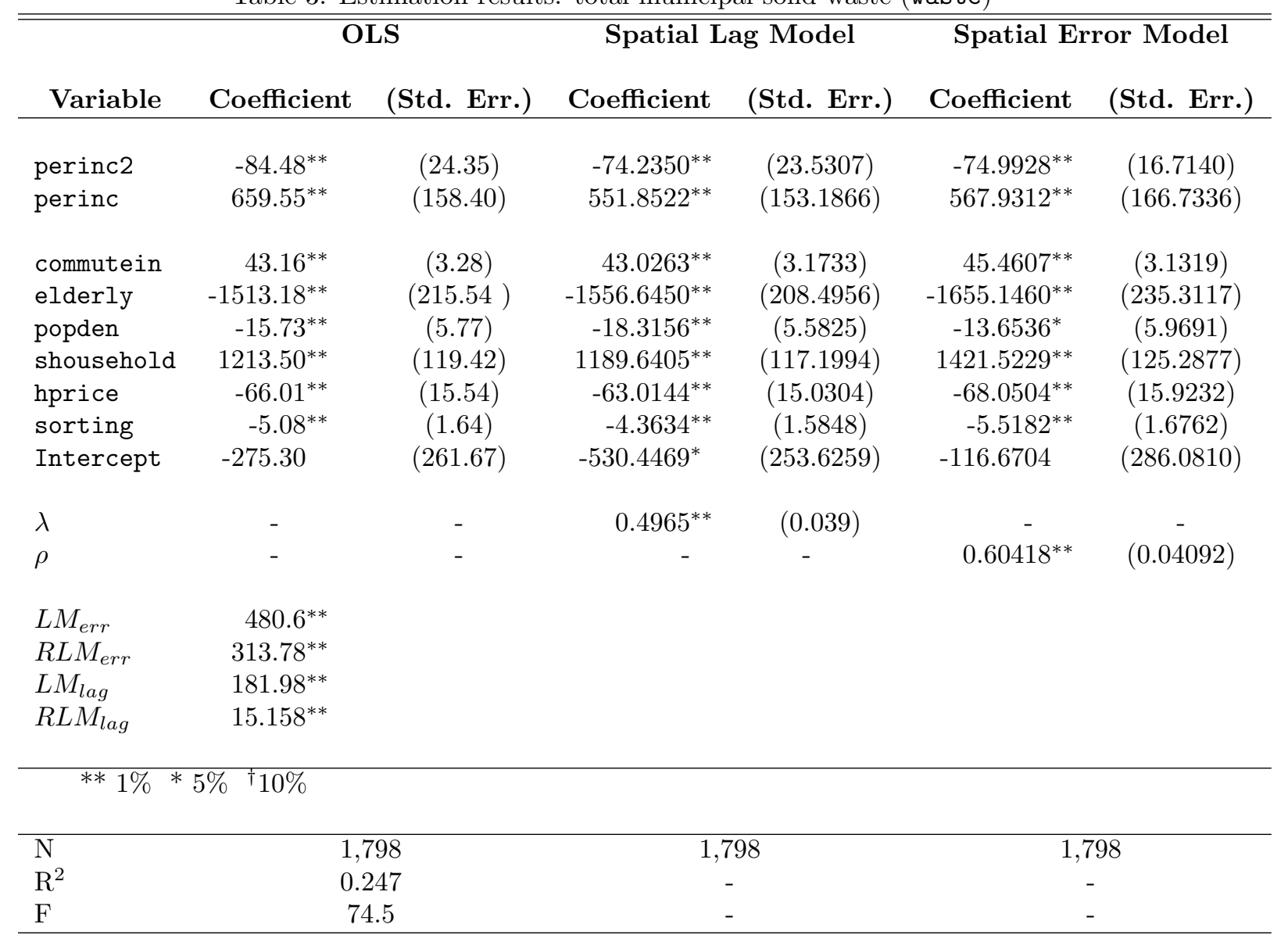


Table 4: Estimation results: household municipal solid wastes (wasteh)

\begin{tabular}{|c|c|c|c|c|c|c|}
\hline \multirow[b]{2}{*}{ Variable } & \multicolumn{2}{|c|}{ OLS } & \multicolumn{2}{|c|}{ Spatial Lag Model } & \multicolumn{2}{|c|}{ Spatial Error Model } \\
\hline & Coefficient & (Std. Err.) & Coefficient & (Std. Err.) & Coefficient & (Std. Err.) \\
\hline perinc2 & $-67.17^{* *}$ & $(19.54)$ & $-58.0279^{* *}$ & $(18.8414)$ & $-71.2610^{* *}$ & (19.9811) \\
\hline perinc & $560.57^{* *}$ & $(127.11)$ & $463.2713^{* *}$ & (122.9085) & $578.7416^{* *}$ & $(134.0655)$ \\
\hline commutein & $24.99^{* *}$ & $(2.63)$ & $24.9843^{* *}$ & $(2.5305)$ & $25.7543^{* *}$ & $(2.5253)$ \\
\hline elderly & -255.47 & $(172.96)$ & $-317.3880^{\dagger}$ & (166.4293) & -228.7638 & $(189.0874)$ \\
\hline popden & $-10.09^{*}$ & $(4.63)$ & $-11.5726^{* *}$ & $(4.4566)$ & $-8.1612^{\dagger}$ & $(4.8029)$ \\
\hline shousehold & $421.51^{* *}$ & (95.83) & $398.5679^{* *}$ & (92.5536) & $462.7869^{* *}$ & $(100.7891)$ \\
\hline hprice & $-61.50^{* *}$ & $(12.47)$ & $-61.2803^{* *}$ & $(12.0255)$ & $-69.9480^{* *}$ & $(12.8215)$ \\
\hline sorting & $4.51^{* *}$ & $(1.31)$ & $-4.1663^{* *}$ & $(1.2664)$ & $-5.1510^{* *}$ & $(1.3497)$ \\
\hline Intercept & -330.36 & $(209.98)$ & $-502.8219^{*}$ & $(201.9607)$ & -350.5740 & $(229.7403)$ \\
\hline$\lambda$ & - & - & $0.52558^{*}$ & $(0.04172)$ & - & - \\
\hline$\rho$ & - & - & - & - & $0.58382^{* *}$ & $(0.043002)$ \\
\hline$L M_{e r r}$ & $433.12^{* *}$ & & & & & \\
\hline$R L M_{e r r}$ & $179.21^{* *}$ & & & & & \\
\hline$L M_{l a g}$ & $257.38^{* *}$ & & & & & \\
\hline$R L M_{l a g}$ & $3.4721^{\dagger}$ & & & & & \\
\hline \multicolumn{7}{|c|}{$* * 1 \% * 5 \%{ }^{\dagger} 10 \%$} \\
\hline $\mathrm{N}$ & \multicolumn{2}{|c|}{1,798} & \multicolumn{2}{|c|}{1,798} & \multicolumn{2}{|c|}{1,798} \\
\hline $\mathrm{R}^{2}$ & \multicolumn{2}{|c|}{0.149} & \multicolumn{2}{|c|}{-} & \multicolumn{2}{|c|}{-} \\
\hline $\mathrm{F}$ & \multicolumn{2}{|c|}{40.2} & \multicolumn{2}{|c|}{-} & \multicolumn{2}{|c|}{-} \\
\hline
\end{tabular}


Table 5: Estimation results: business municipal solid wastes (wasteb)

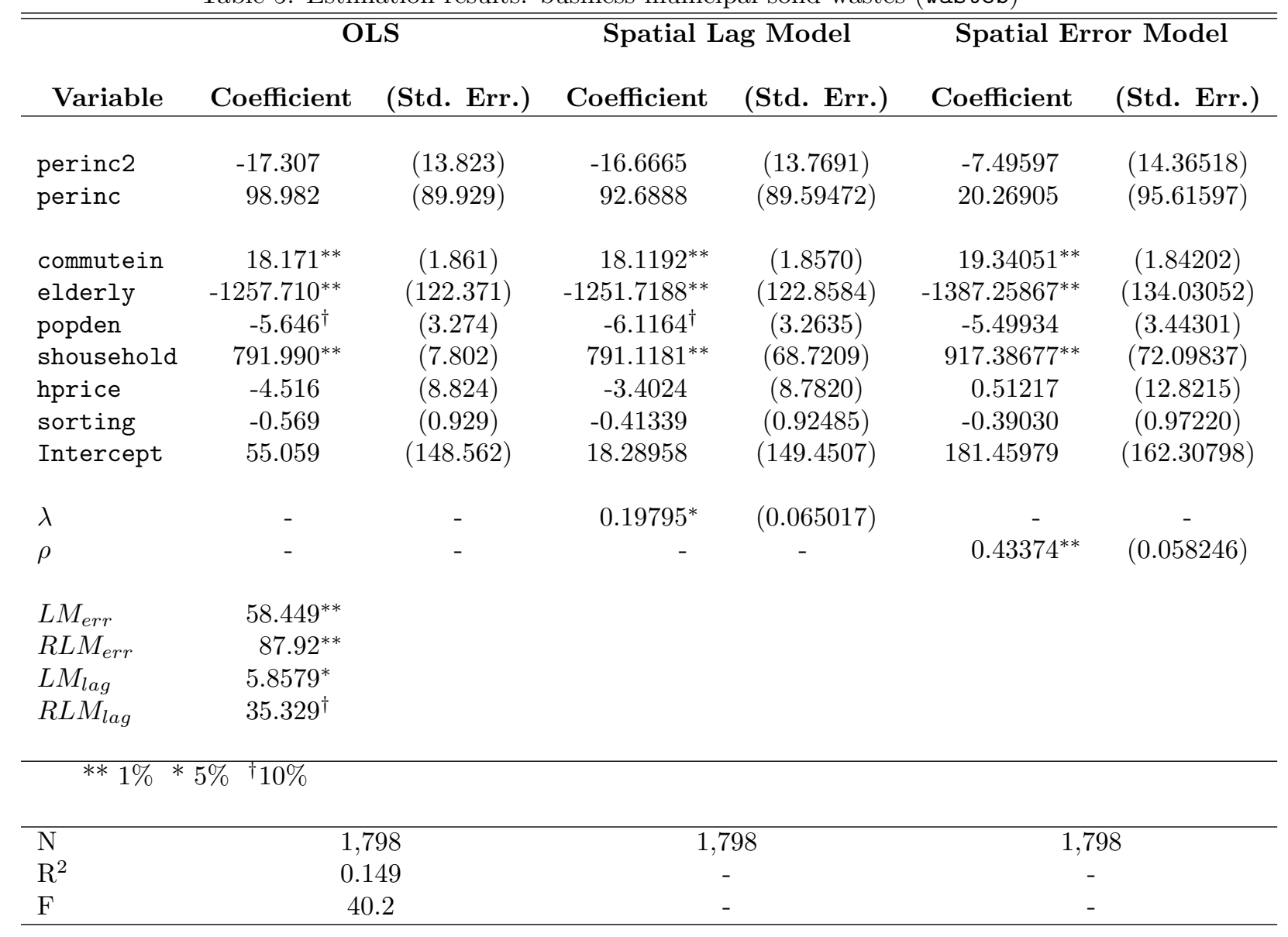


Table 6: Estimation results: landfill (landfill)

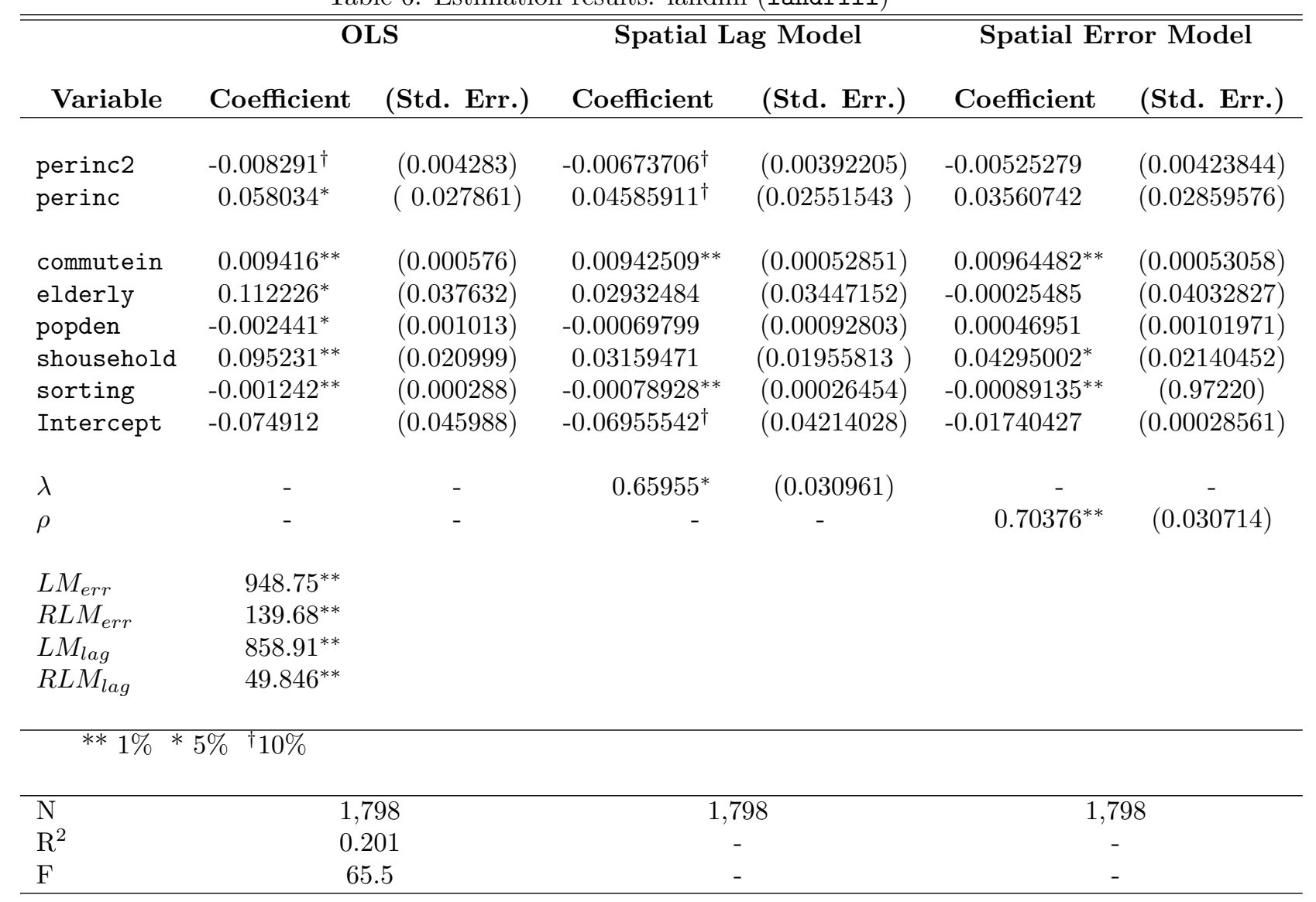


Table 7: Turning points

\begin{tabular}{lrrrr}
\hline & \multicolumn{1}{c}{ waste } & \multicolumn{1}{c}{ wasteh } & \multicolumn{1}{c}{ wasteb } & \multicolumn{1}{c}{ landfill } \\
\hline$\beta_{1}$ & 567.9312 & 578.7416 & 20.2691 & 0.0356 \\
$\beta_{2}$ & -74.9928 & -71.261 & -7.4960 & -0.0053 \\
Turning points & 3.7866 & 4.0607 & 1.3520 & 3.3894 \\
Absolute or relative & absolute & absolute & not sig. & not sig. \\
\hline
\end{tabular}

